\title{
Diapause development and cold hardiness of Pectinophora gossypiella (Lepidoptera: Gelechiidae) larvae in Greece
}

\author{
Olga P. KALTSA ${ }^{1}$, Panagiotis G. MILONAS ${ }^{2 *}$ and Matilda SAVOPOUlOU-SOULTANi ${ }^{1}$ \\ ${ }^{1}$ Laboratory of Applied Zoology and Parasitology, Department of Agriculture, Aristotle University of Thessaloniki, \\ 54124 Thessaloniki, Greece \\ ${ }^{2}$ Benaki Phytopathological Institute, Department of Entomology, Laboratory of Biological Control, 8 S. Delta str., 14561 Kifissia, \\ Attikis, Greece
}

Keywords. Gelechiidae, Pectinophora gossypiella, dormancy, diapause development, cold hardiness, supercooling point, pre-freeze mortality, cotton

\begin{abstract}
Larval diapause development and termination and some characteristics of cold hardiness in Pectinophora gossypiella (Saunders) (Lepidoptera: Gelechiidae) were studied under field conditions in northern Greece. P. gossypiella overwintering larvae were sampled at 20 to 30 day intervals and subjected to two photoperiodic regimes at $20^{\circ} \mathrm{C}$. In larvae kept under a long-day photoperiod $(16 \mathrm{~L}: 8 \mathrm{D})$ diapause development was accelerated compared to those kept under a short-day photoperiod (8L : 16D). There was no difference in response to the two photoperiods after February. Mean number of days to pupation of $P$. gossypiella overwintering larvae decreased progressively through the sampling period, from November to April. Chilling is not a prerequisite but does accelerate diapause development. Supercooling points for $P$. gossypiella overwintering larvae ranged from -14 to $-17^{\circ} \mathrm{C}$ with the majority dying after freezing.
\end{abstract}

\section{INTRODUCTION}

Pectinophora gossypiella (Saunders) (Lepidoptera: Gelechiidae) is one of the most destructive insects attacking cotton fields world-wide. The feeding of the larvae may reduce lint yields by as much as $60 \%$ (Fry et al., 1978) and cause severe economic losses for cotton growers (Henneberry \& Naranjo, 1998). The insect overwinters in diapause as full grown larvae within the seeds or in protected places in the soil. Adult emergence in the south-western United States occurs in late March and continues until late August (Henneberry \& Naranjo, 1998). In Greece $P$. gossypiella completes 3 to 4 generations per year. Diapause induction is triggered by a combination of shortening photoperiod and low temperature (Henneberry \& Naranjo, 1998; Venette et al., 2000).

Diapause and cold hardiness are the basic means by which insects in temperate zones cope with unfavourable environmental conditions (Tauber et al., 1986; Lee, 1991). Photoperiod and temperature are the most common cues involved in the diapause syndrome and cold hardiness of insects (Tauber et al., 1986; Lee, 1991; Irwin et al., 2001). Diapause duration is among others, a critical factor in the survival of insects during unfavourable winter conditions. Diapause is a dynamic process, during which diapause development varies in intensity, and the abiotic or biotic cues necessary to break diapause also change over time ( Tauber et al., 1986; Danks, 1987; Irwin et al., 2001; Hodek, 2002).

Seasonal variation in cold hardiness is reported for a number of overwintering insects (Leather et al., 1993; Block, 1995; Danks, 2005). In many cases this variation is associated with the onset and termination of diapause, although environmental triggers might act, independently of the diapause syndrome, on the accumulation of cryoprotectants and other physiological and biochemical changes resulting in increased cold hardiness (Baust, 1982; Denlinger, 1991; Block, 1995; Hodková \& Hodek, 2004).

Data on the cold tolerance of $P$. gossypiella overwintering larvae are scarce and studies on diapause development under field conditions are restricted to some specific areas (Beasley, 1997; Henneberry \& Jech, 1999; Venette et al., 2000). In this study the diapause development of overwintering larvae of $P$. gossypiella in Greece is reported. In addition, the cold hardiness of overwintering larvae in relation to seasonal changes are also described.

\section{MATERIAL AND METHODS}

\section{Insects}

Bolls were collected from a heavily infested cotton field after harvest in November, 1999 and kept under field conditions protected from rain and direct sunlight until the following May. The field was located in northern Greece close to the city of Thessaloniki (latitude $40.5^{\circ} \mathrm{N}$ ).

\section{Diapause termination}

For the study of diapause development in the field 50 overwintering larvae from bolls, kept under field conditions, were transferred to the laboratory at 20 to 30 days intervals during the winter of 1999-2000. Larvae were placed in Petri dishes with a piece of paper towel and kept either under a long-day $(16 \mathrm{~L}$ : $8 \mathrm{D})$ or a short-day photoperiod $(8 \mathrm{~L}: 16 \mathrm{D})$ at $20^{\circ} \mathrm{C}$ in controlled environment chambers (Precision Scientific, General Electric, Louisville, KY). Pupation was recorded daily and pupae were

\footnotetext{
* Corresponding author; e-mail: biocon@bpi.gr
} 
TABLE 1. Mean number of days ( \pm SEM) to pupation for overwintering larvae of $P$. gossypiella sampled during the winter in Greece.

\begin{tabular}{ccc}
\hline \multirow{2}{*}{ Transfer date } & \multicolumn{2}{c}{ Photoperiodic regime $(\mathrm{L}: \mathrm{D})$} \\
\cline { 2 - 3 } & $16: 8$ & $8: 16$ \\
\hline 24 Nov. 99 & $127 \pm 5.38 \mathrm{a}^{1} \mathrm{~A}$ & $184 \pm 11.4 \mathrm{aB}$ \\
28 Dec. 99 & $110 \pm 5.92 \mathrm{aA}$ & $161 \pm 9.5 \mathrm{abB}$ \\
24 Jan. 00 & $76 \pm 5.46 \mathrm{bA}$ & $121 \pm 9.71 \mathrm{bB}$ \\
25 Feb. 00 & $63 \pm 3.61 \mathrm{bcA}$ & $75 \pm 8.82 \mathrm{cA}$ \\
15 Mar. 00 & $50 \pm 7.48 \mathrm{cdA}$ & $79 \pm 9.17 \mathrm{cA}$ \\
1 Apr. 00 & $37 \pm 5.06 \mathrm{dA}$ & $60 \pm 11.06 \mathrm{cA}$ \\
25 Apr. 00 & $28 \pm 3.76 \mathrm{dA}$ & $53 \pm 7.98 \mathrm{cB}$ \\
\hline
\end{tabular}

${ }^{1}$ Means followed by the same latter within a column and by the same capital letter within a row are not significantly different (Tukey HSD, $\mathrm{P}=0.05$ ).

placed individually in plastic cells until adult emergence. As there is no morphological criterion for discriminating diapausing larva, pupation after transfer to the laboratory was used as a criterion for the end of diapause development.

\section{Diapause intensity}

Overwintering larvae were collected from two major cottongrowing regions of Greece. One in the north of Greece (Thessaloniki) and one $200 \mathrm{~km}$ far to the south, in central Greece (Larissa). The two areas are separated by Mount Olympus, the highest mountain in Greece $(2.918 \mathrm{~m})$. Both populations were collected in early November before the onset of low temperatures in these areas. Two hundred larvae from each population were placed in 10 Petri dishes (20 per Petri-dish) and kept at $5^{\circ} \mathrm{C}$ for 15 or 30 days in continuous darkness to avoid any potential influence of photoperiod on diapause development. After this the larvae were maintained at $20^{\circ} \mathrm{C}$ under a short-day photoperiod (8L : 16D) and the number pupated recorded daily. The mean number of days to pupation was used as a criterion of diapause intensity. The duration of diapause under the specific environmental conditions was used to measure diapause intensity, in the sense of Masaki (2002).

\section{Determination of super cooling point (SCP)}

In the winter of 1999, 15 overwintering larvae from the field were transferred to the laboratory at monthly intervals starting from December until May 2000. Each larva was placed individually in a transparent plastic capsule $(16 \times 7 \mathrm{~mm})$ and immobilised with cotton. A copper constantan thermocouple was attached to the larvae (Digitron 2000T, Kalestead Ltd, UK) to monitor its temperature. The capsule containing the larva and the sensor was placed in a test tube, which was then immersed in a circulating bath (Model 9505, Polyscience) containing a solution of ethylene glycol and water. The cooling rate was set at $1{ }^{\circ} \mathrm{C} / \mathrm{min}$. The temperature of a larva when its body fluids crystallized and released latent heat was recorded as the SCP of that individual.

\section{Determination of lethal temperature and lethal time}

In the winter of 1999-2000 the cold tolerance of overwintering larvae of $P$. gossypiella was determined on three occasions. Larvae were placed in test tubes and then immersed in a circulating bath which was cooled gradually to temperatures rangeing between -3 and $-9^{\circ} \mathrm{C}$. After reaching a particular temperature the larvae were kept at this temperature for $2 \mathrm{~h}$. Larvae were then left to warm up gradually to ambient and kept in the laboratory at $25^{\circ} \mathrm{C}$. Larvae that did not respond to mechanical stimuli a few hours later were considered to be dead. The live
TABLE 2. Anova results of the affect of photoperiod and transfer date on the diapause development of overwintering larvae of $P$. gossypiella.

\begin{tabular}{lcccc}
\hline Source & df & MS & F & P \\
\hline Photoperiod & 1 & 72319.5 & 64.45 & $<0.000$ \\
Transfer date & 6 & 75404.7 & 67.20 & $<0.000$ \\
Ph. ${ }^{*}$ Tr. date & 6 & 2645.6 & 2.36 & 0.031 \\
Error & 244 & 1122.2 & & \\
\hline
\end{tabular}

larvae were transferred to $20^{\circ} \mathrm{C}(16 \mathrm{~L}: 8 \mathrm{D})$ and mortality assessed daily. The mortality that occurred after exposure to -3 , -6 , or $-9^{\circ} \mathrm{C}$ for various periods of time was used to estimate lethal time. For determining of Ltime50 and Ltime90 in days, groups of overwintering larvae were exposed for different lengths of time (from $3 \mathrm{~h}$ to 15 days depending on the temperature) to a constant temperature. Larvae were transferred to each specific temperature directly from the culture. Upon removal from the low temperature treatment they were kept in the laboratory $\left(25^{\circ} \mathrm{C}\right)$ for a few hours and mortality assessed daily after the living larvae were transferred to $20^{\circ} \mathrm{C}, 16 \mathrm{~L}: 8 \mathrm{D}$. In each experiment there was 4 replicates of 10 larvae.

\section{Statistical analysis}

Mean developmental time to pupation and adult emergence of overwintering $P$. gossypiella larvae were estimated for each sampling date and photoperiodic regime. A two-way analysis of variance (ANOVA) was deployed to discriminate any effect of sampling date and photoperiod on diapause development, measured as the mean time required for pupation and adult emergence. The t-test was used to compare means for the two photoperiods at each sampling date. The effect of temperature and location on diapause intensity measured as the mean time to pupation was estimated using ANOVA (SPSS, 2000). The influence of sampling date and sex on SCP was determined by ANOVA. Probit analysis was used to estimate the lower lethal temperature of each experimental group and the length of exposure needed to kill a given percentage of the population at each temperature. Chi-square test was used to compare the survival of larvae during the overwintering period.

\section{RESULTS}

\section{Diapause termination}

The duration in days to pupation of overwintering $P$. gossypiella larvae was significantly reduced within the

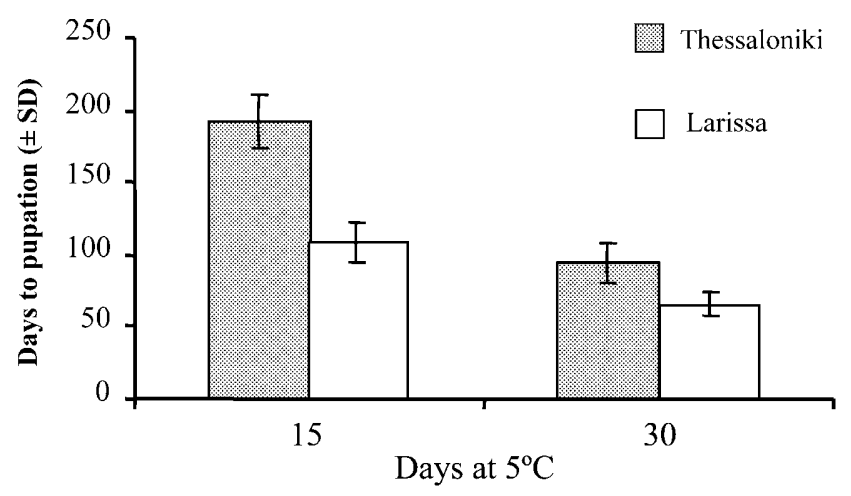

Fig. 1. Mean number of days to pupation of overwintering $P$. gossypiella larvae from two locations kept at $20^{\circ} \mathrm{C}$ and a photoperiod of $8 \mathrm{~L}: 16 \mathrm{D}$, after exposure to $5^{\circ} \mathrm{C}$ for 15 and 30 days, respectively. 


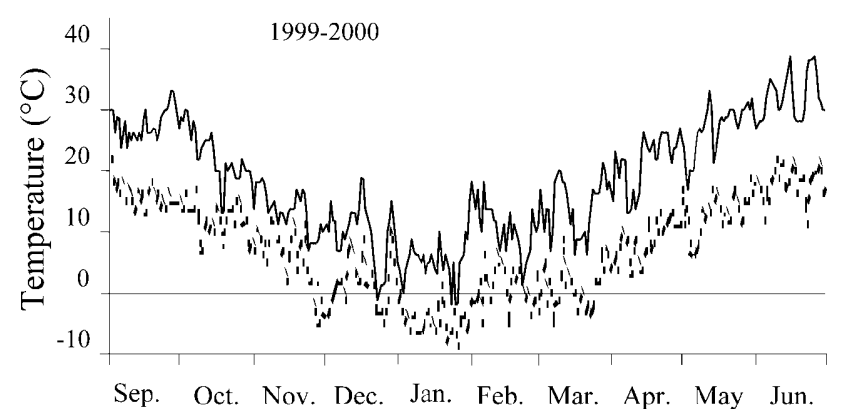

Fig. 2. Daily minimum and maximum air temperatures from September to June, 1999-2000.

sampling period, November to April, when they experienced either a long-day $\left(\mathrm{F}_{6,126}=52.05 ; \mathrm{P}<0.05\right)$ or short-day photoperiod $\left(\mathrm{F}_{6,118}=28.65 ; \mathrm{P}<0.05\right)($ Table 1$)$. Overwintering $P$. gossypiella larvae pupated after 127 days when transferred to the laboratory on $24^{\text {th }}$ November and maintained at a photoperiod of $16 \mathrm{~L}: 8 \mathrm{D}$, whereas those transferred on $1^{\text {st }}$ April pupated after 37 days. The larvae that were transferred to the laboratory on November $24^{\text {th }}$ and maintained at $20^{\circ} \mathrm{C}$ under a photoperiod of $8 \mathrm{~L}: 16 \mathrm{D}$ pupated after 184 days and those transferred on April $1^{\text {st }}$ after 60 days. Mean number of days to pupation gradually declined from autumn to spring at both photoperiods. There was no affect of transfer date on larval development after $25^{\text {th }}$ February. The difference in mean number of days to pupation was significant between the two photoperiodic regimes up to $24^{\text {th }}$ January. Overwintering $P$. gossypiella larvae required more days for pupation under the short than under long-day photoperiods. Photoperiod and sampling date both significantly influenced the diapause development of $P$. gossypiella larvae (Table 2). The interaction between these factors was also significant for diapause development in terms of the mean number of days required for overwintering $P$. gossypiella larvae to pupate (Table 2).

\section{Diapause intensity}

Diapause intensity, measured as the mean number of days to pupation, was significantly affected by location $\left(\mathrm{F}_{1,25}=4.82 ; \mathrm{P}=0.038\right)$ and the time for which larvae were kept at a particular temperature $\left(\mathrm{F}_{1,25}=7.58 ; \mathrm{P}=\right.$ 0.01) (Fig. 1). Larvae from the area of Thessaloniki required more days to pupate than those from Larissa after they were kept for either 15 or 30 days at $5^{\circ} \mathrm{C}$. When larvae from both areas were kept for 30 days at $5^{\circ} \mathrm{C}$ the mean number of days to pupation declined (Fig. 1).

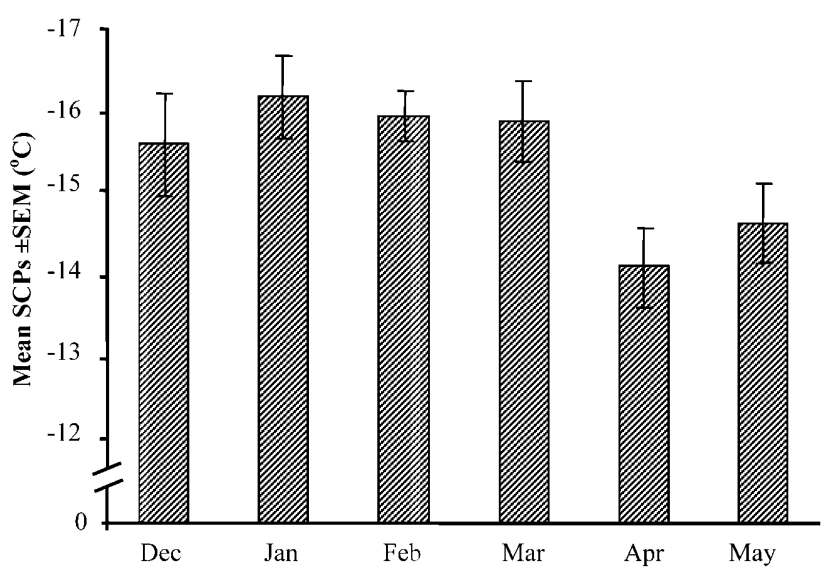

Fig. 3. Seasonal variation in supercooling point of overwintering larvae of $P$. gossypiella.

\section{Cold hardiness}

\section{Supercooling point}

Fig. 2 shows the daily minimum and maximum air temperatures recorded at the field site during the winter of 1999-2000. The seasonal variation in SCP is shown in Fig. 3. The mean SCP of larvae from the field ranged from -14 to $-16.4^{\circ} \mathrm{C}$ and was similar for males and females $\left(\mathrm{F}_{1,81}=2.7 ; \mathrm{P}=0.104\right)$. Within the experimental period variation among sampling dates was not significant $\left(\mathrm{F}_{5,81}=2.09 ; \mathrm{P}=0.075\right)$.

Pre-freeze mortality: Lethal temperature, lethal time

The Ltemp50 and Ltemp90 for overwintering $P$. gossypiella larvae in November, February and May are shown in Table 3. In November the Ltemp50 was significantly higher than in February and May. Accordingly, at each temperature mortality increased with exposure time. There was a substantial reduction in the Ltime 50 and 90 values at the lower temperatures though the differences were not all significant (Table 4). Ltime50 and Ltime 90 were significantly shorter at $-9^{\circ} \mathrm{C}$ than at $-6^{\circ} \mathrm{C}$ and $-3^{\circ} \mathrm{C}$.

\section{DISCUSSION}

In the present study information on diapause termination and cold hardiness of overwintering $P$. gossypiella larvae in Greece is reported which should enhance our understanding of this species phenology. Diapause development in overwintering P. gossypiella larvae in Greece seems to be complete by mid winter (mid February). Larvae collected in the field in February take fewer days to pupate than those transferred to the laboratory in November and December. The fact that larvae collected at different times during winter pupated under both pho-

TABLE 3. Ltemp 50,90 of overwintering larvae of $P$. gossypiella recorded during the winter of 1999-2000 in northern Greece.

\begin{tabular}{ccccccc}
\hline Date & $\mathrm{N}$ & $\mathrm{Slope}$ & $\mathrm{SE}$ & $\mathrm{LT}_{50}(95 \% \mathrm{CI})$ & $\mathrm{LT}_{90}(95 \% \mathrm{CI})$ & $\mathrm{X}^{2}$ \\
\hline November & 119 & -0.21 & 0.08 & $-6.69[-7.71-(-4.05)]$ & $-12.5[-26.6-(-4.1)]$ & 1.47 \\
February & 119 & -0.28 & 0.11 & $-9.2[-14.55-(-8.26)]$ & $-13.7[-32.9-(-11)]$ & 3.65 \\
May & 120 & -0.17 & 0.08 & $-7.4[-10.36-(-5.09)]$ & $-14.6[-64.3-(-11)]$ & 2.56 \\
\hline
\end{tabular}


TABLE 4. Ltime $_{50,90}$ of overwintering larvae of $P$. gossypiella recorded during the winter of 1999-2000 in northern Greece.

\begin{tabular}{ccccccc}
\hline Temp. $\left({ }^{\circ} \mathrm{C}\right)$ & $\mathrm{N}$ & Slope & $\mathrm{SE}$ & $\mathrm{LT}_{50}(95 \% \mathrm{CI})($ days $)$ & $\mathrm{LT}_{90}(95 \%)($ days $)$ & $\mathrm{X}^{2}$ \\
\hline-3 & 75 & 2.02 & 0.76 & $8.54(4.18-13.21)$ & $36.69(19.16-2187.1)$ & 2.11 \\
-6 & 100 & 1.84 & 0.59 & $2.36(0.78-3.37)$ & $11.74(7.26-73.9)$ & 1.52 \\
-9 & 75 & 2.55 & 0.82 & $0.13(-0.08-0.19)$ & $0.38(0.30-0.68)$ & 0.18 \\
\hline
\end{tabular}

toperiodic regimes suggests that low temperature is not a prerequisite for diapause development and termination, although they might promote diapause development (Tauber et al., 1986). Despite the fact that diapause development ended in early February, the first pupation in the field occurred at the end of April. Low temperatures that prevail at that time suppress larval development, which is resumed in spring. This phenomenon is reported for other species of insects in the same general area of northern Greece (Milonas \& Savopoulou-Soultani, 2004). It is the means by which this insect synchronises its spring emergence as suggested for other species (Tauber et al., 1986; Fantinou et al., 1998).

Photoperiod is known to influence diapause development in many insects that live in temperate areas (Tauber et al., 1986). In our case diapause development was accelerated under long-days. Exposure to short-days kept the larvae collected in November and January in diapause. Short days prevail at that time. By responding to short days diapause development is decreased and high temperatures early in winter do not terminate diapause.

Diapause intensity is a physiological trait measured as the duration of diapause under specific conditions (Masaki, 2002).

Duration of diapause affects the time of its termination. In $P$. gossypiella, diapause intensity determines the time of diapause termination in the field. Tauber et al. (1986) report that in most temperate zone insects, which undergo an autumnal-hibernal diapause, the specific stimulus responsible for diapause termination is unknown. The sensitivity these insects show to inducing and maintenance factors diminishes progressively and diapause terminates spontaneously during winter. The time of diapause termination depends on its intensity, which is predetermined for each species, as well as for each strain of a species (Tauber et al., 1986). In this study the time for which they were exposed to $5^{\circ} \mathrm{C}$ increased diapause development at each location. Furthermore, the difference in diapause intensity between the two areas possibly reflects the geographic variation in diapause shown by this species (Gomi, 1997). The two sites are major cotton growing areas in Greece, but the growing period is much shorter in Thessaloniki due to the shorter period of favourable temperatures for the growth of cotton. Thus, the difference in diapause intensity reflects the adaptation of the species to each locality.

Overwintering $P$. gossypiella larvae are very cold hardy. Supercooling points were between -14.6 to $-17.1^{\circ} \mathrm{C}$ and did not differ significantly over the sampling period. Overwintering insects cope with subzero temperatures in one of two ways (Block, 1995). They are either freeze-tolerant or freeze-intolerant. The majority of $P$. gossypiella larvae died after freezing, indicating that they cannot tolerate freezing. On all three occasions significant mortality occurred at temperatures above the SCP, which indicates chilling injury.

Prefreeze mortality also occurred in overwintering larvae of $P$. gossypiella. Mortality at temperatures above the SCP depend on the temperature and duration of exposure. In all cases the presence of chilling injury is documented. Many studies have shown that supercooling point is not a reliable index of insect cold hardiness as it does not take into account the mortality caused at sub-zero temperatures above the insect's supercooling point (Bennett \& Lee, 1989; Bale, 1993). As pointed out by Renault et al. (2002) deleterious effects (including death) can be produced by prolonged exposures to lethal low temperatures even if the insect does not freeze. Finally, during long-term exposure to low temperatures, insects may die from starvation. This is well illustrated by the ability of diapausing larvae collected from the field in the USA of withstanding $5^{\circ} \mathrm{C}$ for $60 \mathrm{~d}$ after which $90 \%$ mortality occurred (Venette et al., 2000).

The difference in Ltemp50 of field maintained larvae between November and February accords with the finding that diapause development is completed in February. The end of diapause development is often accompanied by several changes in the composition of haemolymph. Levels of glycerol and other cryoprotectants are often lower after diapause development is completed (Pullin, 1996).

Our results suggest that $P$. gossypiella is well able to survive the winter conditions in the cotton growing area of northern Greece and that the intensity of diapause in the southern population is weaker.

\section{REFERENCES}

BALE J.S. 1993: Classes of insect cold hardiness. Funct. Ecol. 7: 751-753.

Baust J.G. 1982: Environmental triggers to cold hardening. Compar. Biochem. Physiol. (A) 73: 563-570.

BEASLEY C.A. 1997: Effects of environmental conditions on diapause in native populations of pink bollworm. Southwest. Entomol. 22: 11-27.

BennetT L.E. \& Lee R.E. 1989: Simulated winter to summer transition in diapause adults of the lady beetle (Hippodamia convergens): supercooling point is not indicative of coldhardiness. Physiol. Entomol. 14: 361-367.

Block W. 1995: Insects and freezing. Sci. Progr. 78: 349-372.

DanKs H.V. 1987: Insect Dormancy: An Ecophysiological Perspective. Biological Survey of Canada, Ottawa, $439 \mathrm{pp}$.

DANKS H.V. 2005: Key themes in the study of seasonal adaptations in insects I. Patterns of cold hardiness. Appl. Entomol. Zool. 40: 199-211. 
Denlinger D.L. 1991: Relationship between cold hardiness and diapause. In Lee R.E. \& Denlinger D.L. (eds): Insect at Low Temperature. Chapman \& Hall, New York, pp. 174-198.

Fantinou A.A., Tsitsipis J.A. \& Karandinos M.G. 1998: Diapause termination in Sesamia nonagrioides (Lepidoptera: Noctuidae) under laboratory and field conditions. Envir. Entomol. 27: 53-58.

Fry K.E., Kittock D.L. \& Henneberry T.J. 1978: Effects of number of pink bollworm larvae per boll on yield and quality of pima and upland cotton. J. Econ. Entomol. 71: 499-502.

Gomi T. 1997: Geographic variation in critical photoperiod for diapause induction and its temperature dependence in Hyphantria cunea Drury (Lepidoptera: Arctiidae). Oecologia 111: $160-165$.

Henneberry T.J. \& JeCH L.F. 1999: Pink bollworm (Lepidoptera: Gelechiidae): Diapause larval exit from cotton bolls, larval and pupal development and mortality, and spring moth emergence in the insectary and in the field. Southwest. Entomol. 24: 281-300

HENNEBERRY T.J. \& NARANJo S.E. 1998: Integrated management approaches for pink bollworm in the southwestern United States. Integr. Pest Manag. Rev. 3: 31-52.

Hodek I. 2002: Controversial aspects of diapause development. Eur. J. Entomol. 99: 163-173.

Hodková M. \& Hodek I. 2004: Photoperiod, diapause and coldhardiness. Eur. J. Entomol. 101: 445-458.

IRwin J.T., Bennett V.A. \& LeE R.E.JR. 2001: Diapause development in frozen larvae of the goldenrod gall fly Eurosta soli- daginis Fitch (Diptera: Teprhritidae). J. Compar. Physiol. (B) 171: $181-188$.

Leather S.L., Walters K.F.A. \& Bale J.S. 1993: The Ecology of Insect Overwintering. Cambridge University Press, Cambridge, $255 \mathrm{pp}$.

LeE R.E. 1991: Principles of insect low temperature tolerance. In Lee R.E. \& Denlinger D.L. (eds): Insect at Low Temperature. Chapman \& Hall, New York, pp. 17-46.

MASAKI S. 2002: Ecophysiological consequences of variability in diapause intensity. Eur. J. Entomol. 99: 143-154.

Milonas P.G. \& Savopoulou-Soultani M. 2004: Diapause termination in overwintering larvae of a Greek strain of Adoxophyes orana (Lepidoptera: Tortricidae). Environ. Entomol. 33: 513-519.

Pullin A.S. 1996: Physiological relationships between insect diapause and cold tolerance: Coevolution or coincidence? Eur. J. Entomol. 93: 121-129.

Renault D., Salin C., Vannier G. \& Vernon P. 2002: Survival at low temperatures in insects: What is the ecological significance of the supercooling point? Cryo-Letters 23: 217-228.

SPSS 2000: I, version 10.0 SPSS, Chigaco IL.

Tauber M.J., Tauber C.A. \& Masaki S. 1986: Seasonal Adaptations of Insects. Oxford University Press, New York, 411 pp.

Venette R.C., Naranjo S.E. \& Hutchison W.D. 2000: Implications of larval mortality at low temperatures and high soil moistures for establishment of pink bollworm (Lepidoptera: Gelechiidae) in south eastern United States cotton. Environ. Entomol. 29: 1018-1026.

Received October 20, 2005; revised and accepted December 9, 2005 